\title{
Reflecting on a career not yet lived: student Schwartz Rounds
}

\author{
Michael Zervos ${ }^{1}$ and Faye Gishen ${ }^{2}$ \\ ${ }^{1}$ Torbay \& South Devon NHS Foundation Trust, Torquay, Devon, UK ${ }^{2}$ University College London \\ Medical School, London, UK
}

Reflective practice Schwartz Rounds (SRs) were introduced to University College London Medical School (UCLMS) in 2014, the first medical school internationally to introduce SRs specifically for undergraduates. In the intervening 5 years, SRs have become a feature of the medical degree (MBBS) syllabus, as the next generation of doctors acquires skills to manage the pressures associated with a lifelong career in medicine. This piece will discuss how SRs have worked at UCLMS, and how they contribute to the resilience and wellbeing of today's medical students and tomorrow's doctors.

Schwartz Rounds are a group reflective practice forum which provides an opportunity for staff from all disciplines to reflect on the emotional aspects of their work. ${ }^{1}$ The Schwartz Centre for Compassionate Healthcare was established in 1995 as the legacy of Kenneth Schwartz, a health care attorney who died of lung cancer at the age of 41 years. What he and his family valued most during this period were the small acts of human kindness that helped 'make the unbearable, bearable'. 2 SRs follow a universal format: a multidisciplnary panel each present a story on a clinical theme or case, followed by a non-problem-solving audience discussion, led by trained facilitators. The semantics of a 'story' are key - it is not a case presentation, but rather a narrative that explores how that clinician felt, and what they have taken away from the encounter.

Schwartz Rounds aim to reinforce the humanity in health care, bringing empathy to the fore and enhancing communication between patients, caregivers and colleagues. ${ }^{3}$ These aspects may be relatively undervalued during early medical education, where a premium is placed upon academic success and progression. Once immersed in clinical encounters, medical students are expected to shift this paradigm and to juggle academic achievement with the development of a clinical persona. They form connections with patients, with the inherent risks that patients may not improve or survive. Feeling like an anonymous face in a sea of medical students makes it challenging to initiate meaningful dialogues about these encounters. Students may seek protective mechanisms, with some tending to avoid or dismiss their emotions because they are not equipped with the appropriate reflective tools. Students also question where they belong in a patient's journey, being neither a layperson nor yet a doctor, and similar issues arise in the educational journey of other health care students, including nurses. 4

Similar to other medical schools and health care institutions, UCLMS offers a variety of reflective opportunities in recognition of the fact that different people reflect in different ways: written versus oral; shared versus private. Our student feedback suggests that written reflective assignments are sometimes produced as perfunctory pieces of work to be arbitrarily marked, rather than as a tool to develop the nascent clinician. Thus, we introduced Schwartz Rounds as a way to diversify reflective opportunities beyond written work, which we found to be increasingly viewed with scepticism in the wake of the Bawa-Garba case. 5 FG had used SRs for many years in her clinical practice, and felt that they could transfer well to the educational community. MZ, with an anthropological back- ground and an interest in mental health and well-being, became the first medical student internationally to train as an SR facilitator, and has remained involved with UCLMS reflective practice after graduation. 
Schwartz Rounds at UCLMS have been themed for each clinical year group, focusing on topics that have emerged from feedback. For example, an SR was held for final-year students that focused on 'My first day' with a multidisciplinary panel sharing stories of starting in practice. This has subsequently been recognised by the Point of Care Foundation as the 'Most powerful round' in the 2019 Schwartz Awards. In hearing stories of clinicians' first days, they were reminded that no one goes through a health care career alone, and that although it may be intimidating, feelings of trepidation, shock, fear, guilt, hope, and awe are normal. One story centred around a very powerful demonstration of solidarity and empowerment between nurses, and the panellist described how proud she felt to be part of a united community. Other SRs have centred on coping with witnessing death and suffering, managing uncertainty in medicine, and courage.

A repeating theme in the students' feedback is the gratitude that they feel towards the panellists for sharing their stories, finding it easier to identify, empathise, and work with them thereafter. In participating, panellists make them- selves vulnerable, with stories frequently including components of shame, distress, or guilt. We have often sought a senior member of UCLMS to participate and appreciate their contributions for this added dimension of role modelling vulnerability.

Potential barriers to the success of the model include the continuing costs of purchasing the intellectual property, the time commitment of facilitators and panellists, and acceptance of the paradigm shift from 'normal' medical school activities (small group work, and questions with a right or wrong answer, etc.) to the open-ended nature of an SR. By endorsing SRs, UCLMS has avowed the importance of open discussion, listening to its students' concerns and prioritising their well-being.

Schwartz Rounds present an opportunity to bring the human elements centre stage for health care learners and embed healthy reflective habits. Our students learn by example that reflection is a positive tool that can be carried through to clinical practice. We hope to expand SRs, enhancing the teamwork and multidisciplinary team (MDT) aspects by inviting a multidisciplinary health care student audience. Providing a forum to discuss the complexities of a challenging but rewarding career has helped us to better support our students, and we hope will have benefits on their health and well-being, both as students and as practitioners.

\section{REFERENCES}

1. Point of Care Foundation. About Schwartz Rounds. Available at https ://www.pointofcarefoundation.org. uk/our-work/schwartz-rounds/. Accessed on 10 May 2019.

2. The Schwartz Centre for Compassionate Healthcare. About us. Available at https://www. theschwartzcenter.org/about-us/. Accessed on 10 May 2019.

3. Barker R, Cornwell J, Gishen F. Introducing compassion into the education of health care profes- sionals; can Schwartz Rounds help? Journal of Compassionate Healthcare 2016;3:3.

4. Taylor C, Xyrichis A, Leamy M, Reynolds E, Maben J. Can Schwartz Center Rounds support healthcare staff with emotional challenges at work, and how do they compare to other interventions aimed at providing similar support? A sys- tematic review and scoping review. BMJ Open 2018;8(10):e024254. 
5. Dyer C, Cohen C. How should doc- tors use e-portfolios in the wake of the Bawa-Garba case? BMJ

2018;360:k572.

410 (c) 2019 John Wiley \& Sons Ltd and The Association for the Study of Medical Education. THE CLINICAL TEACHER 2019; 16: 409-411

Corresponding author's contact details: Michael Zervos, Doctors Mess, Torbay Hospital, Newton Road, Torquay TQ2 7AA, UK. E-mail: michael.zervos@nhs.net

Funding: None

Conflict of interest: None

Acknowledgements: With thanks for the support from UCLMS and POCF. Ethical approval: None

doi: $10.1111 /$ tct. 13049 